\title{
A HIGH POWER-DENSITY, SELF-SUSTAINED HYBRID BIO-SOLAR CELL WITH CO-CULTURE OF HETEROTROPHIC AND PHOTOSYNTHETIC BACTERIA
}

\author{
$X$. Wei, W. Yang, and S. Choi ${ }^{*}$
}

\author{
Bioelectronics and Microsystems Laboratory, Department of Electrical and Computer Engineering, \\ State University of New York at Binghamton, New York, USA
}

\begin{abstract}
We demonstrated self-sustainable high power generation from a microliter-scale bio-solar cell by using syntrophic interaction between electricity-generating heterotrophic bacteria and phototrophs. The device continuously generated light-responsive electricity from the heterotrophic bacterial metabolic respiration with the organic substrates produced by the photosynthetic bacteria. Without the external input of organic fuels, the bio-solar cell utilizing the mixed culture generated self-sustained current more than 400 times greater than that of the bio-solar cell using only photosynthetic bacteria. The device featured (i) a small-scale microchamber to reduce the start-up time by increasing the probability of cell attachment/biofilm formation, (ii) a carbonbased anodic material to promote bacterial adhesion and (iii) a sandwich configuration of the anode/proton exchange membrane (PEM)/air-cathode to minimize the inter-electrode distance and significantly reduce the internal resistance.
\end{abstract}

\section{INTRODUCTION}

With increasing concerns about the energy crisis and global warming, heterotrophic microbial fuel cells (MFCs) have been a major focus for renewable energy production [1-5]. The MFCs are powered by live heterotrophic bacteria to efficiently degrade a broad range of organic substrates under natural conditions and offer clean and sustainable features. Although the MFCs are capable of generating a high power density, they require a continuous supply of organic substrate for energy, hampering the entirely self-sustainable power supply. On the other hand, bio-solar cells are another type of the MFC that can provide self-sustainable power generation by using the photosynthetic and respiratory activities of photosynthetic bacteria [1,6-10]. The bio-solar cell can continuously generate electricity from solar energy without additional organic substrates since light energy absorbed by the photosynthetic reaction splits water and generates oxygen, protons, and electrons. Despite their promise as a self-sustainable power source, however, the bio-solar cells have not yet been successfully translated into commercial applications because of their persistent power limits. Their power densities, which are typically several orders of magnitude lower than that of even the smallest power MFCs [11, 12], remain a significant challenge.

Recently, the "Plug and Play" photosynthetic concept has been proposed by the Johnes' group at Arizona State University as a strategy to increase bio-solar cell performance; the light and dark reactions can operate independently, coupling microbial respiratory metabolism to electricity generation using photosynthetic co-cultures [13]. Also, several research teams generated a wealth of new scientific and technological results that clearly demonstrated synergistic cooperation between photosynthetic microorganisms and heterotrophic bacteria [14-16]. However, much of this work is still in its nascent stages; the evolution of this technology will require additional exploration through practical application of established techniques and comprehensive systematic integration.

In this work, we created a microfluidic bio-solar cell that integrated both heterotrophic and photosynthetic bacteria for high power density and self-sustainability. The heterotrophic bacterial

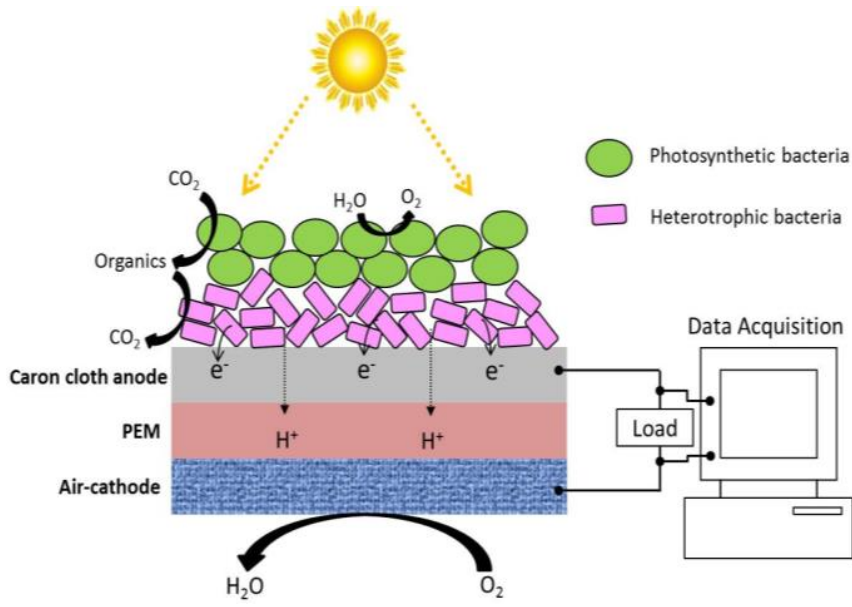

Figure 1: Conceptual illustration of the hybrid bio-solar cell based on the synergistic cooperation between photosynthetic bacteria and heterotrophic bacteria

biofilm (Shewanella oneidensis MR-1), which formed first at the bottom of the anode, oxidized organic substrates and efficiently transferred electrons to the anode while photosynthetic bacterial biofilm (Synechocystis sp. PCC 6803) formed over the heterotrophic bacteria and provided the in-situ organic substrates (Fig. 1). Without the external input of organic fuels, the bio-solar cell utilizing the mixed culture generated self-sustained current more than 400 times greater than that of the bio-solar cell using only photosynthetic bacteria. Furthermore, bio-solar cell miniaturization inherently produced favorable conditions for increasing power density by reducing internal resistance and improving mass transport $[17,18]$ while greater bacterial adhesion was promoted by using the carbon-based anode materials compared to an inefficient conventional inorganic materials [11, 17]. In addition, a sandwich configuration of the anode/proton exchange membrane (PEM)/air-cathode minimized the interelectrode distance and significantly reduced the internal resistance [12].

\section{EXPERIMENTAL SET-UP \\ Operating principle}

In this hybrid bio-solar cell, the main biocatalyst to generate electricity was the heterotrophic bacteria. The bacteria extracellularly transfer electrons to the anode while they oxidize organic substrates in the micro-chamber [19]. The phototrophic biofilm formed over the heterotrophic bacteria captures solar energy to convert carbon dioxide and water (generated from heterotroph's respiratory reactions) into oxygen and organic matter, which are subsequently used for both bacterial respiratory reactions (Fig 1), offering self-sustainable and self-maintainable features. During those reactions, electrons are released through extracellular electron transfer pathways and flow to the cathode through the external electrical circuit. Released protons 


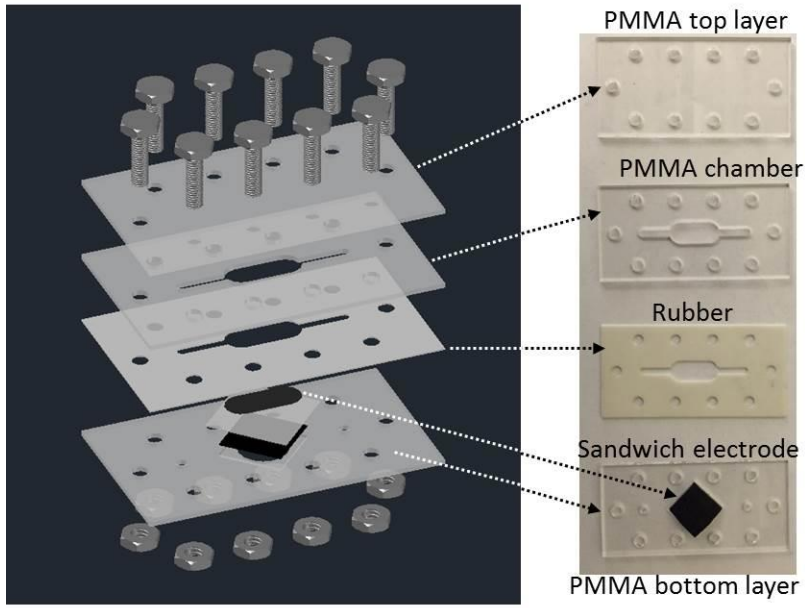

Figure 2: Schematic diagram of the individual layers for the device.



Figure 3: Photo-images of the fully assembled biological solar cell: (a) the bottom view and (b) the top view

simultaneously diffuse from the anodic chamber to the cathode, where they re-combine with electrons and oxygen to re-form water. The photosynthetic bacteria themselves can also be biocatalysts to continuously harvest electrons from microbial photosynthetic and respiratory activities under day-night cycles [20-22]. However, their electron transfer efficiencies are low and not practical to be used as a practical power source $[11,12]$.

\section{Device Fabrication}

The bio-solar cell was assembled as shown in Fig 2 \& Fig 3, where the main body of the device was comprised of four polymethly methacrylate (PMMA) substrates and the sandwiched electrode assembly. Five different functional layers were cut by the laser cutting machine (Universal Laser System,VLS3.5): (i) a top PMMA layer, (ii) a PMMA microfluidic chamber layer, (iii) a rubber gasket, (vi) an anode/PEM (Nafion 117)/air-cathode sandwiched electrode assembly, and (v) a bottom PMMA layer. All layers were carefully aligned and assembled with 10 small screws. The device utilized the air-cathode to allow freely available oxygen to act as an electron acceptor by the installation of the catalyst side of the air-cathode to face toward the chamber while the opposite side was exposed to air. The air-cathode was fabricated from $30 \%$ wet-proofed carbon cloth with four layers of polytetrafluoroethylene (PTFE) coating [23, 24]. The other side of the cathode was coated with $\mathrm{Pt} / \mathrm{C}$ catalysts $(0.5 \mathrm{mg} / \mathrm{cm} 2 \mathrm{Pt}$ loading $)$. The electrodes were pierced with a $0.5 \mathrm{~mm}$ thick $\mathrm{Ti}$ wire as a current collector. The bio-solar cell had two holes for fluidic



Figure 4: Photo-images of (a) the bio-solar cell with cocultures and (b) the enlarged image of the chamber, showing green colored photosynthetic bacteria.

inlet/outlet. Tubes (CODAN, $0.35 \mathrm{~mL}$ volume) were plugged into the holes with adhesive to form a fluidic channel. The $1.6 \mathrm{~mm}$-thick PMMA microfluidic chamber layer (ii) and $0.508 \mathrm{~mm}$-thick rubber gasket layer (iii) were precisely laser-machined to define a $90 \mu \mathrm{L}$ chamber over the electrodes. The size of a completely assembled device was $6 \mathrm{~cm} \times 3.5 \mathrm{~cm}$. The assembled device was sterilized with $70 \%$ ethanol and ultraviolet light for 24 hours.

\section{Inoculum and Catholyte}

Synechocystis sp. PCC 6803 (phototrophs) were grown from $80^{\circ} \mathrm{C}$ glycerol stock cultures by inoculating $15 \mathrm{~mL}$ of BG-11 medium with gentle shaking under a $24 \mathrm{~h}$ light cycle $(12 \mathrm{~h}$ light/dark). The BG-11 contained $1.5 \mathrm{~g} \mathrm{NaNO}_{3}, 40 \mathrm{mg} \mathrm{K} \mathrm{HPO}_{4}, 75$ $\mathrm{mg} \mathrm{MgSO}$, $36 \mathrm{mg} \mathrm{CaCl}, 1 \mathrm{mg}$ of EDTA, and $6 \mathrm{mg}$ of citric acid and of ferric ammonium citrate per $1 \mathrm{~L}$ of distilled water. The continuous aeration and illumination were provided by fluorescent lamps for 2 weeks. Growth was monitored by measurement of the optical density at $600 \mathrm{~nm}\left(\mathrm{OD}_{600}\right)$ and the culture we used reached an $\mathrm{OD}_{600}$ of 1.4. Shewanella oneidensis MR-1 (heterotrophs) were grown from $-80^{\circ} \mathrm{C}$ glycerol stock cultures by inoculating $20 \mathrm{~mL}$ of L-broth medium with gentle shaking in air for $24 \mathrm{~h}$ at $35^{\circ} \mathrm{C}$. The Lbroth media consisted of $10.0 \mathrm{~g}$ tryptone, $5.0 \mathrm{~g}$ yeast extract and $5.0 \mathrm{~g} \mathrm{NaCl}$ per liter. The culture we used reached an $\mathrm{OD}_{600}$ of 2.0. Both cultures were then centrifuged at $5,000 \mathrm{rpm}$ for $5 \mathrm{~min}$ to remove the supernatant. The bacterial cells were re-suspended in a new medium and used as an anolyte for the device.

\section{Measurement Setup}

We measured the potentials between the anodes and the cathodes with a data acquisition system (National instrument, USB-6212), and recorded the readings every $1 \mathrm{~min}$ via a customized LabView interface. An external resistor connected between the anode and the cathode closed the circuit. The current through this resistor was calculated using Ohm's law.

\section{RESULTS AND DISCUSSION \\ Biofilm formation}

In this work, we constructed a hybrid bio-solar cell comprised of two microbes, namely Shewanella oneidensis MR-1 

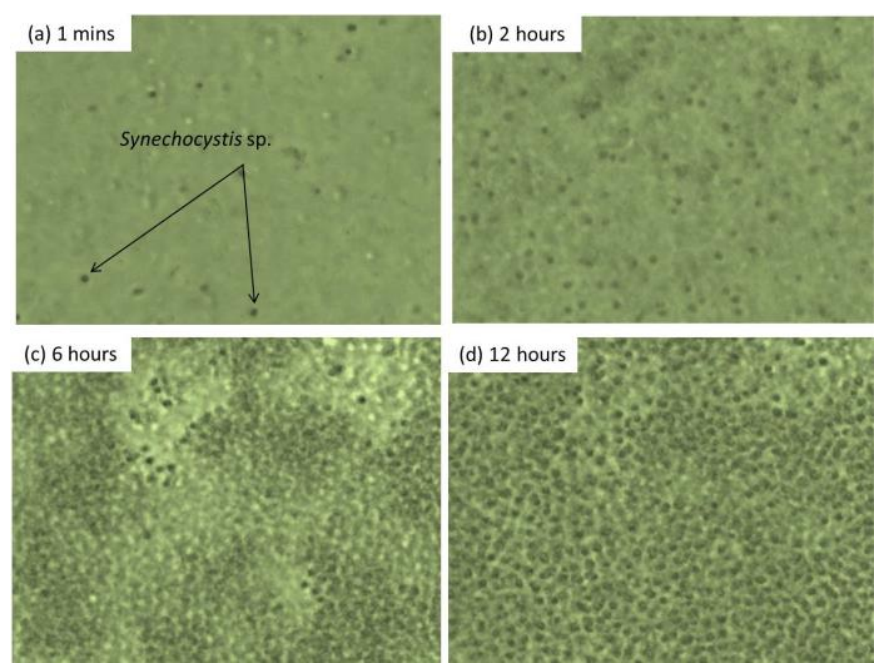

Figure 5: Photosynthetic bacterial biofilm formed on heterotrophic bacterial biofilm. The extracellular polymeric substance of the heterotrophic microbes facilitate the adhesion of phototrophic ones rapidly forming their biofilm.

(heterotrophic) and Synechocystis sp. PCC 6803 (photosynthetic). For better understanding of the biofilm formation, we used our previous microfabricated MFC designed for both optical and electrical studies of the bacteria [25, 26]. The MFC included a transparent thin gold as an anode and a protruded anode chamber, which could be directly placed under an optical microscope for observing live bacterial behavior. After the heterotrophic bacterial biofilm was first formed, photosynthetic bacterial inoculum was introduced (Fig. 4). Although further study needs to be done, we could claim that the biofilm extracellular polymeric substance of the heterotrophic microbes might facilitate adhesion of phototrophic microbes rapidly forming their biofilm. In this way, cultivating photosynthetic bacterial biofilms could be maximized by using co-cultures with heterotrophic bacteria. Fig 5 shows the rapid ( $<12$ hours) and densely-packed biofilm formation of the phototrophs over the heterotrophic bacterial biofilm.

\section{Current generation}

The efficiency of photosynthetic electron transfer can also be improved via co-cultures with heterotrophic bacteria. This statement is based on the fact that electron transfer rate among heterotrophic bacteria is much more efficient than that of photosynthetic bacteria, which leads to significantly increased power generation in the absence of an electron donor [4]. Although the understanding of the individual and synergistic roles for key microbial populations is still missing, some studies have already shown increased power generation from mixed microbial communities [5-7]. The bio-solar cell utilizing the mixed culture generated light-responsive current from organic matter released by the photosynthetic bacteria. Without external introduction of organic substrates, the bio-solar cell with co-cultures generated self-sustained current density $\left(6 \mu \mathrm{A} / \mathrm{cm}^{2}\right)$ (Fig 6a), which was more than 400 times greater than that of the bio-solar cell using only photosynthetic bacteria $\left(15 \mathrm{nA} / \mathrm{cm}^{2}\right)$ (Fig. 6b). During operation at $12 \mathrm{~h} / 12 \mathrm{~h}$ light/dark cycles, the device with the co-cultures shows the negative light response (Fig 6b) which is consistent with the mechanism where photosynthetic bacteria produces organic fuels that feed heterotrophic bacteria, and the respiratory electrontransfer chain of the heterotrophic bacteria is the source of electrons deposited on an anode. A current decrease during


Figure 6: Current densities measured from the (a) photosynthetic bacteria only and (b) co-cultures of Shewanella oneidensis MR-1 and Synechocystis sp. PCC 6803. The white bars indicate the illuminated period and the shadow indicates the dark period.

illumination was presumably due to the negative impact of photosynthetically evolved oxygen. While the oxygen abiotically reacted with the anode decreasing the open circuit voltage of the device, it could also compete with electron transfers of the heterotrophic bacteria and, therefore, decrease the current generation. Approximately a four-fold higher current was generated during the dark than during the illumination.

On the other hand, a positive light response was observed from the bio-solar cell loaded only with photosynthetic bacteria; approximately a three-fold increase was generated during the $12 \mathrm{~h}$ of illumination than during the dark phases. This positive light response indicates that the photosynthetic electron transfer chain is the source of the electrons harvested on the anode. During the dark periods, bacterial respiration produced energy from the organic substrates (which is the product of photosynthesis) to keep the current generation above zero.

\section{CONCLUSION}

In this work, we created a microfluidic bio-solar cell which continuously generated an entirely self-sustainable current by using syntrophic interaction between heterotrophic biocatalysts and 
photosynthetic bacteria. We could generate much higher current density $\left(6 \mu \mathrm{A} / \mathrm{cm}^{2}\right)$ than that of the bio-solar cell using only photosynthetic bacteria. Moreover, by using an innovative device architecture in a miniaturized chamber, the bacterial adhesion was improved and the internal device resistance was reduced, leading to higher current/power generation. This work could result in barrier-transcending advancements in miniature bio-solar cells that could facilitate higher performance with self-sustainability, releasing bio-solar cell technology from its restriction to research settings, and translating it to practical, real-world applications.

\section{ACKNOLOWDGMENT}

We would like to thank the Nano-fabrication Lab at SUNYBinghamton for providing the fabrication facilities and the Binghamton University Research Foundation for funding this work.

\section{REFERENCES}

[1] S. Choi, "Microscale microbial fuel cells: advances and challenges", Biosensors and Bioelectronics, 69, 8-25 (2015).

[2] D.R. Lovley, "Electromicrobiology", Annu. Rev. Microbiol., 66, 391-409 (2012)

[3] B.E. Rittmann, "Opportunities for Renewable bioenergy using microorganisms", Biotechnology and Bioengineering, 100, 203-212 (2008).

[4] J. Babauta, R. Renslow, Z. Lewandowski, and H. Beyenal, "Electrochemically active biofilms: facts and fiction", Biofouling: The journal of Bioadhesion and Biofilm Research, 28, 789-812 (2013)

[5] V.B. Oliveira, M. Simoes, L.F. Melo, and A.M.F.R. Pinto, "Overview on the developments of microbial fuel cells", Biochemical Engineering Journal, 73, 53-64 (2013).

[6] H. Lee and S. Choi, "A micro-sized biosolar cell for selfsustaining power generation", Lab Chip, 15, 391-398 (2015).

[7] A.J. McCormick, P. Bombelli, A.M. Scott, A.J. Philips, A.G. Smith, A.C. Fisher, and C. J. Howe, "Photosynthetic biofilms in pure culture harness solar energy in a mediatorless biophotovoltaic cell system", Energy \& Environmental Science, 4, 4699-4709 (2011).

[8] A.J. McCormick, P. Bombelli, D.J. Lea-Smith, B.W. Bradley, A.M. Scott, A.C. Fisher, A.G. Smith, and C. J. Howe, "Hydrogen production through oxygenic photosynthesis using the cyanobacterium Synechocystis sp. PCC6803 in a biophotoelectrolysis cell system", Energy \& Environmental Science, 6, 2682-2690 (2013)

[9] P. Bombelli, M. Zarrouati, R.J. Thorne, K. Schneider, S.J.L. Rowden, A. Alik, K. Yunus, P.J. Cameron, A.C. Fisher, D.I. Wilson, C. J. Howe, and A.J. McCormick, "Surface morphology and surface energy of anode materials influence power outputs in a multi-channel mediatorless bio-photovoltaic system", Phys. Chem. Chem. Phys., 14, 12221-12229 (2012).

[10] R.W. Bradley, P. Bombelli, D.J. Lea-Smith, and C.J. Howe, "Terminal oxidase mutants of the cyanobacterium Synechocystis sp. PCC6803 show increased electrogenic activity in biological photo-voltaic systems", Phys. Chem. Chem. Phys., 15, 13611-13618 (2013).

[11] S. Choi, H.-S. Lee, Y. Yang, P. Parameswaran, C.I. Torres, B.E. Rittmann and J. Chae, "A $\mu \mathrm{L}$-scale Micromachined Microbial Fuel Cell Having High Power Density", Lab Chip, 11, 1110-1117 (2011).

[12] X. Wei, H. Lee, and S. Choi, "Biopower generation in a microfluidic bio-solar panel", Sensors \& Actuators: B. Chemical, 228, 151-155 (2016)
[13] A.K. Jones, "Plug and play photosynthesis", Chemistry \& Industry, 76, 42-45 (2012).

[14] Z. He, J. Kan, F. Mansfeld, L.T. Angenent, and K.H. Nealson, "Self-Sustained Phototrophic microbial fuel cells based on the synergistic cooperation between photosynthetic microorganisms and heterotrophic bacteria", Environ. Sci. Technol., 43, 1648-1654 (2009).

[15] K. Nishio, K. Hashimoto, and K. Watanabe, "Light/electricity conversion by defined co-cultures of Chlamydomonas and Geobacter", Journal of Bioscience and Bioengineering, 115, 412-417 (2013)

[16] J. P. Badalamenti, C.I. Torres, and R. Krajmalnik-Brown, "Coupling Dark Metabolism to Electricity Generation Using Photosynthetic Co-cultures", Biotechnology and Bioengineering, 111, 223-231 (2014).

[17] F. Qian and D.E. Morse, "Miniaturizing microbial fuel cells", Trends in Biotechnology, 29, 62-69 (2011).

[18] H. Wang, A. Bernarda, C. Huang, D. Lee and J. Chang, "Micro-sized microbial fuel cell: A mini-review", Bioresource Technology, 102, 235-243 (2011).

[19] C.I. Torres, A.K. Marcus, H. Lee, P. Parameswarn, R. Krajmalnik-Brown, and B.E. Rittmann, "A kinetic perspective on extracellular electron transfer by anode-respiring bacteria", FEMS Microbiol Rev., 34, 3-17 (2010).

[20] M. Rosenbaum, Z. He, and L.T. Angenent, "Light energy to bioelectricity: photosynthetic microbial fuel cells", Current Opinion in Biotechnology, 21, 259-264 (2010).

[21] D. Strik, R.A. Timmers, M. Helder, K. Steinbusch, H Hamelers, and C.J.N. Buisman, "Microbial solar cells: applying photosynthetic and electrochemically active organisms," Trends in Biotechnology, 29, 41-49 (2011).

[22] R.W. Bradley, P. Bombelli, S. Rowden, and C.J. Howe, "Biological photovoltaics: intra- and extra-cellular electron transport by cyanobacteria", Biochemical Society Transactions, 40, 1302-1307 (2012).

[23] X. Zhang, J. Shi, P. Liang, J. Wei, X. Huang, C. Zhang, and B.E. Logan, "Power generation by packed-bed air-cathode microbial fuel cells", Bioresource Technology, 142, 109-114 (2013).

[24] X. Zhang, X. Xia, I. Ivanov, X. Huang, and B.E. Logan, "Enhanced activated carbon cathode performance for microbial fuel cell by blending carbon black", Environ. Sci. Technol., 48, 2075-2081 (2014).

[25] C. Dai, S. Chen, A. Fraiwan, and S. Choi, "Direct Visualization of Electrogenic Bacteria in a Microfabricated Microbial Fuel Cell", IEEE SENSORS 2013, Nov. 4 - 6, 2013 , Baltimore, Maryland, USA, pp. 636-639

[26] A. Fraiwan and S. Choi, "A biomicrosystem for simultaneous optical and electrochemical monitoring of electroactive microbial biofilm," IEEE SENSORS 2015, Nov. 1 - 4, 2015, Busan, Korea, pp. 197 - 200

\section{CONTACT}

*S. Choi, tel: +1-607-777-5913; sechoi@binghamton.edu 